\title{
Structural, Optical and Photocatalytic Properties of PVC/CdS Nanocomposites Prepared by Soft Chemistry Method
}

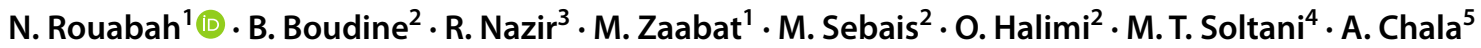

Received: 15 July 2020 / Accepted: 9 September 2020 / Published online: 15 September 2020

(c) Springer Science+Business Media, LLC, part of Springer Nature 2020

\begin{abstract}
This work investigates the preparation of cadmium sulfide nanoparticles (CdS) embedded in the polymeric polyvinylchloride (PVC) matrix. PVC/CdS nanocomposite films were prepared via sol-gel method with deposition by spin-coating on glass substrates. Effects of CdS nanoparticles on the structural, morphological, optical and photocatalytic properties of the synthetized nanocomposite were studied. Results of XRD and Raman analysis confirm the formation of CdS nanoparticles with hexagonal phase in the PVC matrix, with average crystallite size between 17 to $69 \mathrm{~nm}$. The UV-vis spectroscopy reveals that the transmission is between 80 and $95 \%$ in the visible region, and a direct energy bandgap between $4.07 \mathrm{eV}$ for $3.85 \mathrm{eV}$. The PL emission spectra indicate the interstitial cadmium defect states. In addition, the surface modifier (PVC) exert great influence not only on the optical performance of the particles themselves but also on the size distribution of the particle in the PVC matrix. The photocatalytic study shows a good potential of PVC/CdS nanocomposites films for MB degradation under UV light irradiation.
\end{abstract}

Keywords CdS nanoparticles · Sol-gel · Polyvinyl chloride PVC $\cdot$ Photocatalytic

\section{Introduction}

In recent past much attention has been devoted to studies regarding composite polmer-inorganic nanoparticles. The interest in these materials rose due to their biological, optical, electronic and magnetic applications. These potential applications are due to their excellent luminescent and electrical properties [1]. Out of these materials cadmium sulfide (CdS) nanocomposites has been focus of interest

N. Rouabah

nouhadrouabeh@gmail.com

1 Laboratoire des Composants actifs et materiaux, Université Larbi Ben M'Hidi, Oum El Bouaghi, Algeria

2 Laboratoire de Cristallographie, Université des frères Mentouri - Constantine 1, Constantine, Algeria

3 Department of Chemistry, Bilkent University, Bilkent, 06800 Ankara, Turkey

4 Laboratoire de Photonique et nanomatériaux multifonctionnels, Université Mohamed Khider -Biskra, Biskra, Algeria

5 Laboratoire de physique des couches minces et applications LPCMA, Université Mohamed Khider -Biskra, Biskra, Algeria because it is good photosensitive material with potential application in photo-conducting cells and devices, that makes it important material for the application of solar cells, photo-detectors and biological labeling [2]. Reports have reflected that the devices that contain polymer type nanocomposites of inorganic-organic material can be easily processed to produce new properties materials that are better than single segment polymers [3]. Polymer like PVC has attainted tremendous attention in many auspects of life, so it is considered as versatile, beneficial and economical commodity polymers. PVC can be used for indoor construction purposes like sash windows and door shutters due to its easy modification and low cost. PVC can also be used in flooring and water hoses. Besides that PVC can be utilized for different Industrial applications and anti bacterial properties [4]. Photocatalysis is very important and innovative technique to get rid of hazardous pollutants and also it has been a safe tool for determining the photocatalytic efficiency of different semiconductors [5]. The research has revealed that CdS is efficient UV light irradiation catalyst for photocatalysis [6]. A lot of research has been devoted on embedding photocatalysts in the photodegradable PVC for decomposition of plastics. The interest in PVC arrises due to its easy decomposition and not 
generating dioxins under natural conditions [7]. Eventually the embedding $\mathrm{CdS}$ in the conjugated polymer has been focus of interest for the improvement and performance of photocatalysis [8].

In this work, we report a comprehensive study of the effect of dopage of CdS on the PVC of the prepared nanocomposites films synthesized via a sol-gel procedure. We studied the structural, morphological, optical, photoluminescence properties of $\mathrm{PVC} / \mathrm{CdS}$ and its application in photocatalytic activity. For the study of the photocatalytic performance, degradation of MB was performed under UV light irradiation.

\section{Experimental Details}

\subsection{Synthesis of CdS Nanoparticles}

CdS nanoparticles were synthesis via hydrothermal reaction of cadmium nitrate $\left(\mathrm{Cd}\left(\mathrm{NO}_{3}\right)_{2}\right)$ and thiourea dissolved in water for $1 \mathrm{~h}$. After, the mixture was stirred into the Teflon lined autoclave at $180^{\circ} \mathrm{C}$. Then, the obtained products were washed with DI and ethanol. Finally, the CdS powder were formed by several times and dried at $80{ }^{\circ} \mathrm{C}$ for $12 \mathrm{~h}$.

\subsection{Preparation of Polymer Nanocomposites}

About $1 \mathrm{~g}$ of powder PVC was dissolved in $30 \mathrm{~mL}$ of the solvent of Tetrahydrofurane THF. A measured amount (weight depends of loading taken) of cadmium sulfide was dissolved in $10 \mathrm{~mL}$ of THF and added into the polymer solution under continuous stirring for $1 \mathrm{~h}$. The solution was then left to rest; the heaviest particles got deposited under at the bottom of the container. The upper part of this solution, containing the crystallites of smaller sizes, was recovered for the deposition of $\mathrm{PVC} / \mathrm{CdS}$ thin film on the glass. Two-step preliminary to the deposition of PVC/ CdS nanocomposites films, were the cleaning of substrates and the choice of the deposit technique. The deposition technique used for the preparation of composite films, is the technique of centrifugation (spin-coating). $\mathrm{PVC} / \mathrm{CdS}$ nanocomposite was deposited onto glass substrates, before deposition the glass was cleaned for $10 \mathrm{~min}$ approximately with acetone, methanol then double distilled water to eliminate the traces, greases, and impurities onto the glass surface then ameliorate the film adhesion. After that the film was dried to remove moisture. The drying operation was carried out by dry the films to a temperature close to its glass transition temperature $\left(10 \mathrm{~min}\right.$ at $\left.60{ }^{\circ} \mathrm{C}\right)$. This operation allows evaporation of total traces of solvent still present in the polyvinyl chloride.

\subsection{Characterization Techniques}

The crystallographic structure of the films was identified by X-rays diffraction analysis (D8 ADVANCE using $\mathrm{Cu} \mathrm{K \alpha}$ radiation $(\lambda=1.5405 \AA)$. The Raman spectra was collected with a BRUKER Raman SENTERRA R200L spectrometer in the frequency range of $100-800 \mathrm{~cm}^{-1}$. Scanning electron microscopy (SEM) was taken using a Tescan Vega3 (JEOL, Japan). The UV-vis transmittance spectra was recorded using a UV-3101 PC-Shimadzu double-beam spectrophotometer. The photoluminescence (PL) spectra at room temperature was measured with a Perkin-Elmer LS 50B spectrophotometer using He-Cd laser $(\lambda=325 \mathrm{~nm})$.

\subsection{Photocatalytic Procedure}

The photodegradation of MB dye with UV light source (VL215.LC, $15 \mathrm{~W}$ ), the maximum emission is at $365 \mathrm{~nm}$ was used to evaluate the visible light photocatalytic activity of the PVC/CdS nanocomposites and pure PVC. A cylindrical glass vessel containing an aqueous $\mathrm{MB}$ solution $(175 \mathrm{~mL})$ with an initial concentration of $10^{-5} \mathrm{mg} / \mathrm{mL}$. Then, the thin films PVC/CdS nanocomposites of $5 / 2.5 \mathrm{~cm}$ on the side was posed into the petri dish, which contains the MB solutions $(10 \mathrm{~mL})$. After that, the system was subjected to visible light emitted by a $300 \mathrm{~W}$ iodine tungsten lamp (Philips Co). The distance between the surface of the suspension and the light source was about $20 \mathrm{~cm}$. During irradiation, the samples were taken out every $30 \mathrm{~min}$ from the reactor. The clarified solution was analyzed by a $723 \mathrm{UV}-\mathrm{Vis}$ spectrometer (UV1800 Shimadzu LC 2010-HT).

\section{Results and Discussion}

\subsection{Structural Study}

\subsubsection{X-ray Diffraction (XRD) Analysis}

Figure 1 shows the XRD patterns of PVC and PVC/CdS thin films. From the $\mathrm{X}$-ray diffraction spectra, the pure matrice of PVC shows an amorphous structure. However, with the addition of CdS nanoparticles into the PVC matrix, the crystalline nature of the nanocomposite has been obtained. The pattern exhibits prominent broad peak centered at $24.83^{\circ} ; 26.50^{\circ}$ and $28.20^{\circ}$ correspond to the hexagonal phase of $\mathrm{CdS}$ with diffraction planes (100), (002) and (101) respectively with JCPDS data, with preferential orientation along the (002) plane. Nevertheless, the preferential orientation PVC doped with $5 \%$ CdS nanocrystals, corresponds to (002) plane. From 


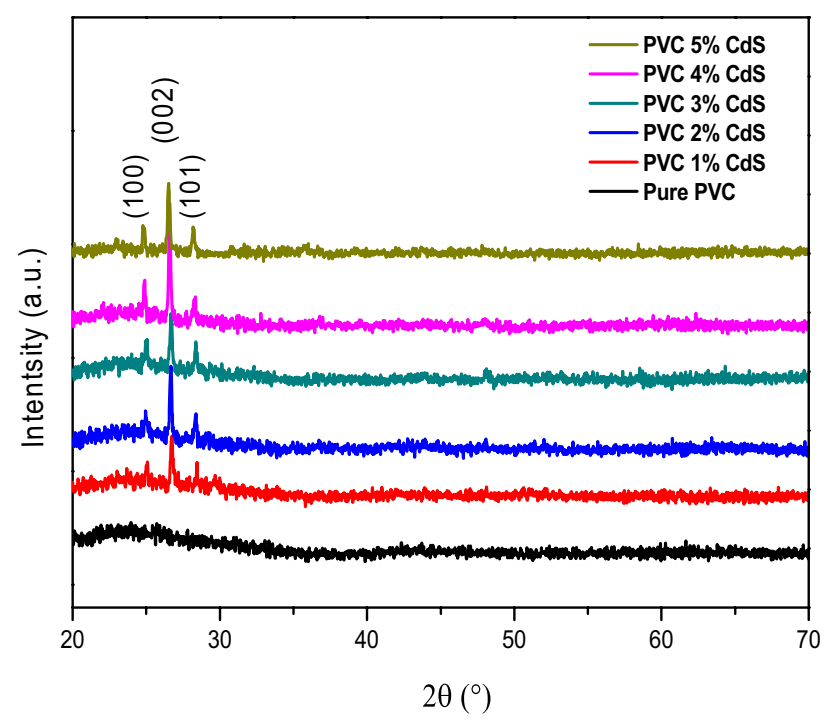

Fig. 1 X-ray diffraction spectra of pure PVC and PVC/CdS nanocomposites thin films

these results, it can be concluded that CdS crystallites are incorporated in the polymer matrix due to the interaction between PVC and CdS. Additionally, it can be seen that the diffraction peaks are considerably broad indicating the fine size of NPs. This broadening may be due to the inhomogeneous strain present in the films [9].

\subsubsection{The Grains Size}

The crystallite size has been calculated by using Debye Scherrer's formula [10], and the computing values are recorded in Table 1:

Table 1 Structural parameters of PVC/CdS nanocomposites thin films

\begin{tabular}{llll}
\hline Samples & $2 \theta\left(^{\circ}\right)$ & $\beta\left(^{\circ}\right)$ & $\mathrm{D}(\mathrm{nm})$ \\
\hline PVC 1\% CdS & 26.73 & 0.14 & 56.91 \\
PVC 2\% CdS & 24.97 & 0.47 & 17.23 \\
& 26.68 & 0.12 & 69.14 \\
& 28.34 & 0.24 & 34.70 \\
PVC 3\% CdS & 25.01 & 0.24 & 37.12 \\
& 26.67 & 0.14 & 59.26 \\
PVC 4\% CdS & 28.37 & 0.24 & 34.70 \\
& 24.91 & 0.16 & 51.70 \\
PVC 5\% CdS & 26.61 & 0.14 & 59.25 \\
& 28.26 & 0.24 & 34.69 \\
& 24.84 & 0.16 & 51.69 \\
& 26.49 & 0.12 & 69.11 \\
& 28.20 & 0.16 & 52.05 \\
\hline
\end{tabular}

$\mathrm{D}=(0.9 \lambda) /(\Delta \theta \cos (\theta))$

where $\beta$ is the full width at half maxima (FWHM) of the peaks, $\theta$ is the diffraction angle, $\lambda$ is the $\mathrm{X}$-ray wavelength (1.5405 ̊).

\subsubsection{Raman Spectroscopy Analysis}

The Raman spectra of pure PVC and PVC/CdS nanocomposites are showing in Fig. 2. The spectrum of pure PVC display a strong peak at $1597 \mathrm{~cm}^{-1}$ ascribed to $\mathrm{C}=\mathrm{C}$ bonds stretching vibrations, and peak at $1351 \mathrm{~cm}^{-1}$, which corresponds to $\mathrm{C}-\mathrm{H}$ bonds bending vibrations $[11,12]$. Additionally, the Raman spectrum of PVC/CdS nanocomposites display two peaks of $\mathrm{CdS}$ hexagonal phase at around $354 \mathrm{~cm}^{-1}$ and $630 \mathrm{~cm}^{-1}$ corresponds to $1 \mathrm{LO}$ and $2 \mathrm{LO}$, respectively, and other peaks at about $680 \mathrm{~cm}^{-1}, 1090 \mathrm{~cm}^{-1}$, and $1317 \mathrm{~cm}^{-1}$ assigned respectively to $\mathrm{C}-\mathrm{Cl}, \mathrm{C}-\mathrm{C}$, and $\mathrm{C}-\mathrm{H}$ stretching vibrations of PVC [13]. The Raman analysis affirmed that our thin films comprised of PVC and CdS elements. Thus, we conclude that the analysis of Raman and XRD are in agreement.

\subsection{Microstructure Properties Morphological Study}

\subsubsection{Scanning Electron Microscopy (SEM) Analysis}

The morphology of PVC/CdS thin films were investigated using SEM. It is important to declare that the SEM image of PVC film has not performed because of its low electrical conductivity that induces the charging effect. Figure $3 \mathrm{a}-\mathrm{d}$ shown some typical PVC/CdS SEM images. As for the $\mathrm{PVC} / \mathrm{CdS}$ nanocomposites, a large number of nanocrystals of CdS on the surface could be seen clearly (Fig. 3), which

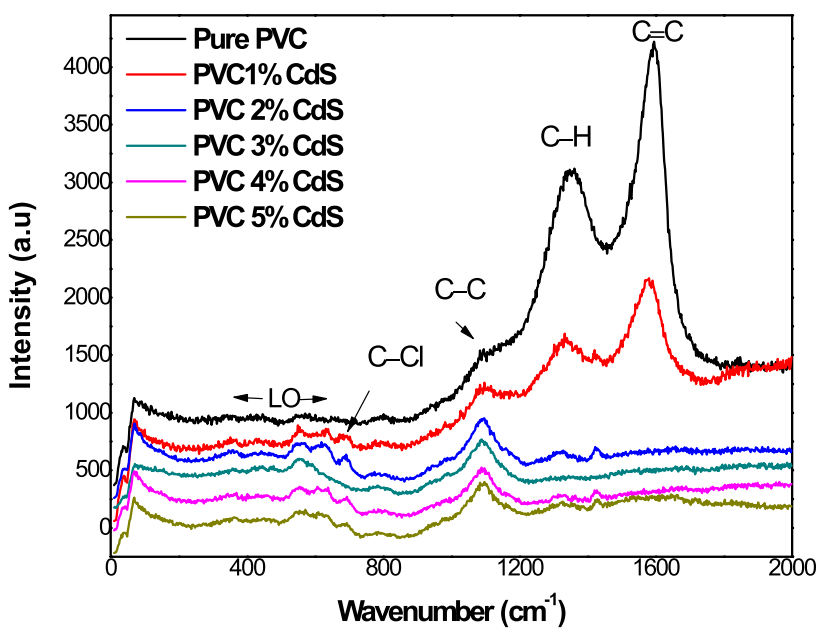

Fig. 2 Raman spectra of pure $\mathrm{PVC}$ and $\mathrm{PVC} / \mathrm{CdS}$ nanocomposites thin films 


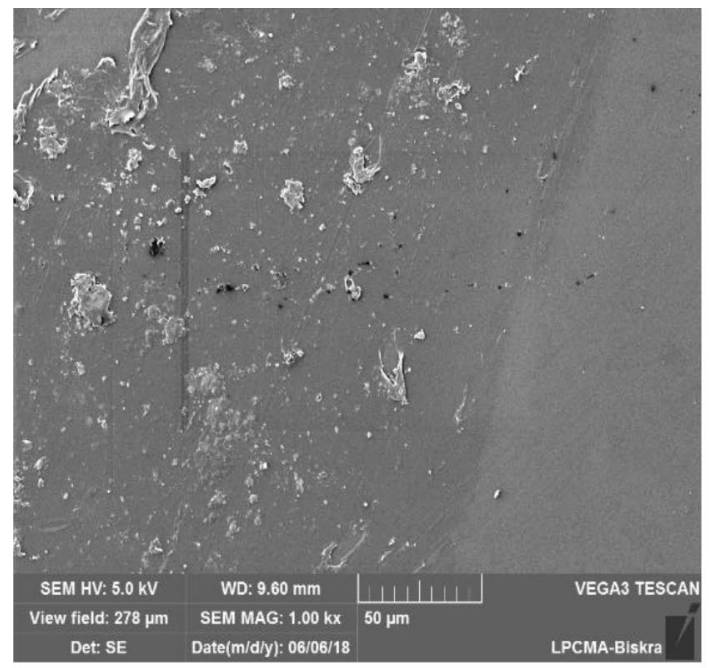

(a)

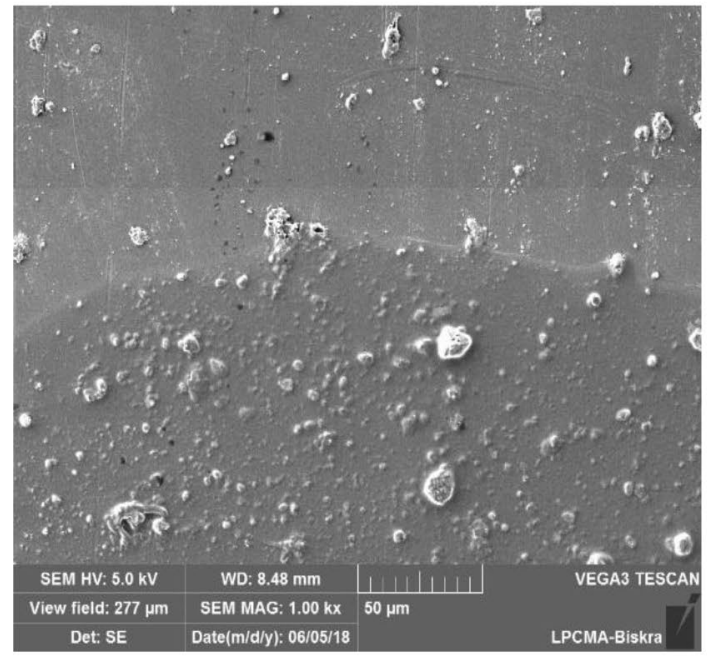

(c)

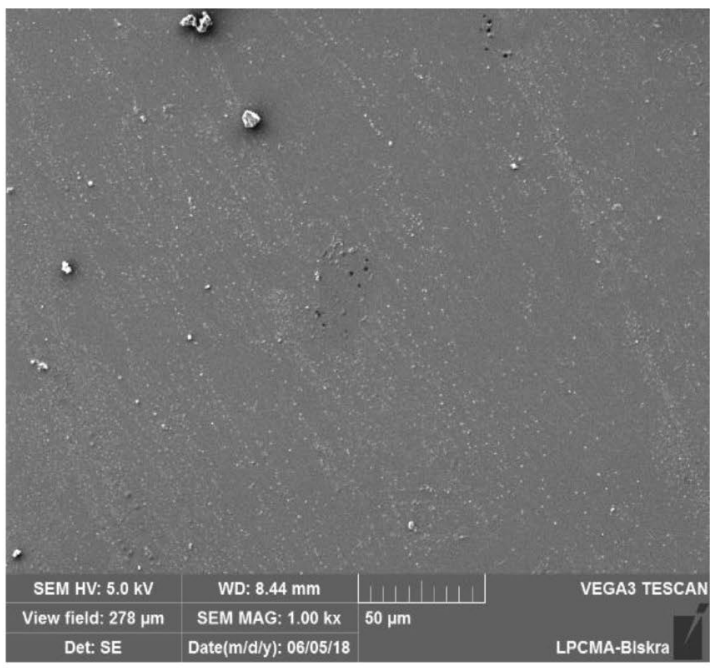

(b)

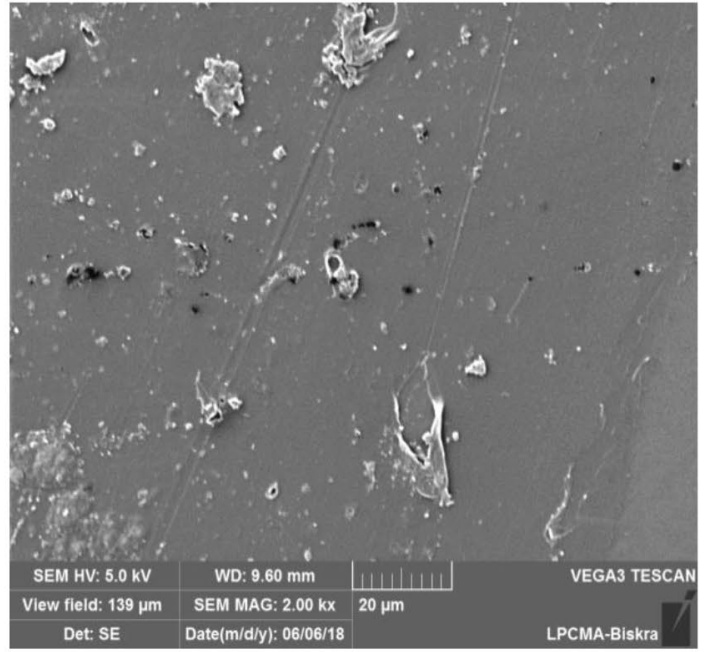

(d)

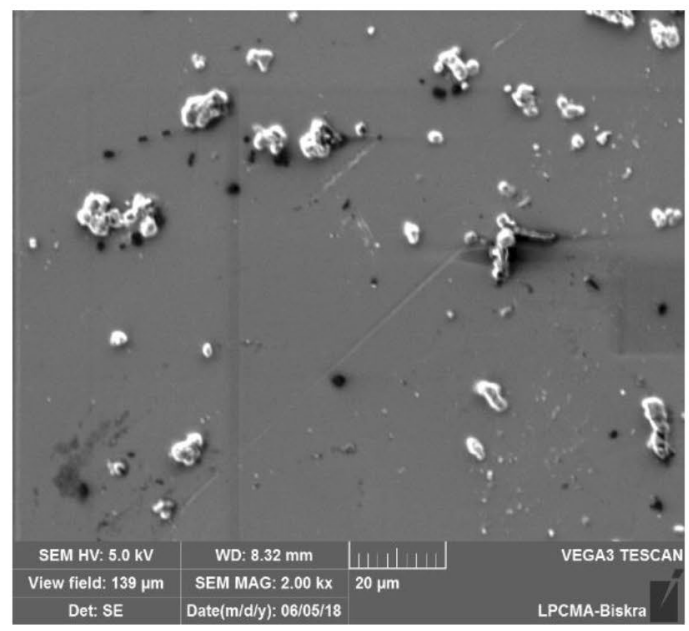

(e)

Fig. 3 SEM images of PVC thin films as a function of CdS nanoparticles content. a PVC 1\% CdS; b PVC 2\% CdS; $\mathbf{c}$ PVC 3\% CdS; d PVC 4\% CdS; e PVC5\% CdS 
led to the surface of the particles becoming rough. In PVC $3 \% \mathrm{CdS}$, the particles of $\mathrm{CdS}$ are agglomerated and have almost uniform dispersion in the PVC matrix.The agglomeration increases with the increase of $\mathrm{CdS}$ nanoparticles. It is maximum for $5 \% \mathrm{CdS}$ nanoparticles in PVC. It is found that at higher $\mathrm{CdS}$ concentration, the density of particles is increase, as well as tiny clusters in spherical shapes are linked together in some rich areas in CdS within the polymers. On the other side, when the CdS lower concentration, some CdS nanoparticles are loosely distributed but some aggregated clusters of varying size can also be found.

Figure 4 displays SEM image of PVC 5\% CdS with different scale $(10 \mu \mathrm{m}, 1 \mu \mathrm{m}$ and $100 \mathrm{~nm})$. It is noted that the CdS nanoparticles fill certain pores on the surface of the PVC. We observe that the size of CdS is mostly nanometric.

\subsection{Optical Study}

\subsubsection{UV-Vis Analysis}

We were using the UV-vis spectra to indicate how the films are transparent in the visible region and to calculate their thickness using the envelope method [14], band gap energy and disorder. The UV-vis spectra of the PVC/CdS

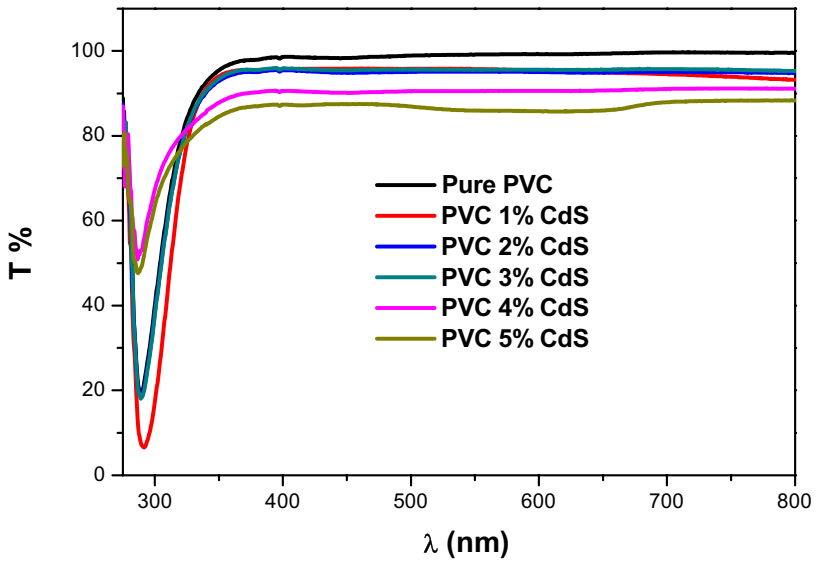

Fig. 5 Optical transmission spectra in the UV-Visible region of pure $\mathrm{PVC}$ and PVC/CdS nanocomposites thin films

nanocomposite films were shown in Fig. 5.In the range 200-800 nm, the pure PVC is fully transparent and has a steep absorption edge at $300 \mathrm{~nm}$. An obvious excitation absorption near $350 \mathrm{~nm}$ means a narrow distribution of nano $\mathrm{CdS}$ in the matrix. For the $400-280 \mathrm{~nm}$ range, we observe a
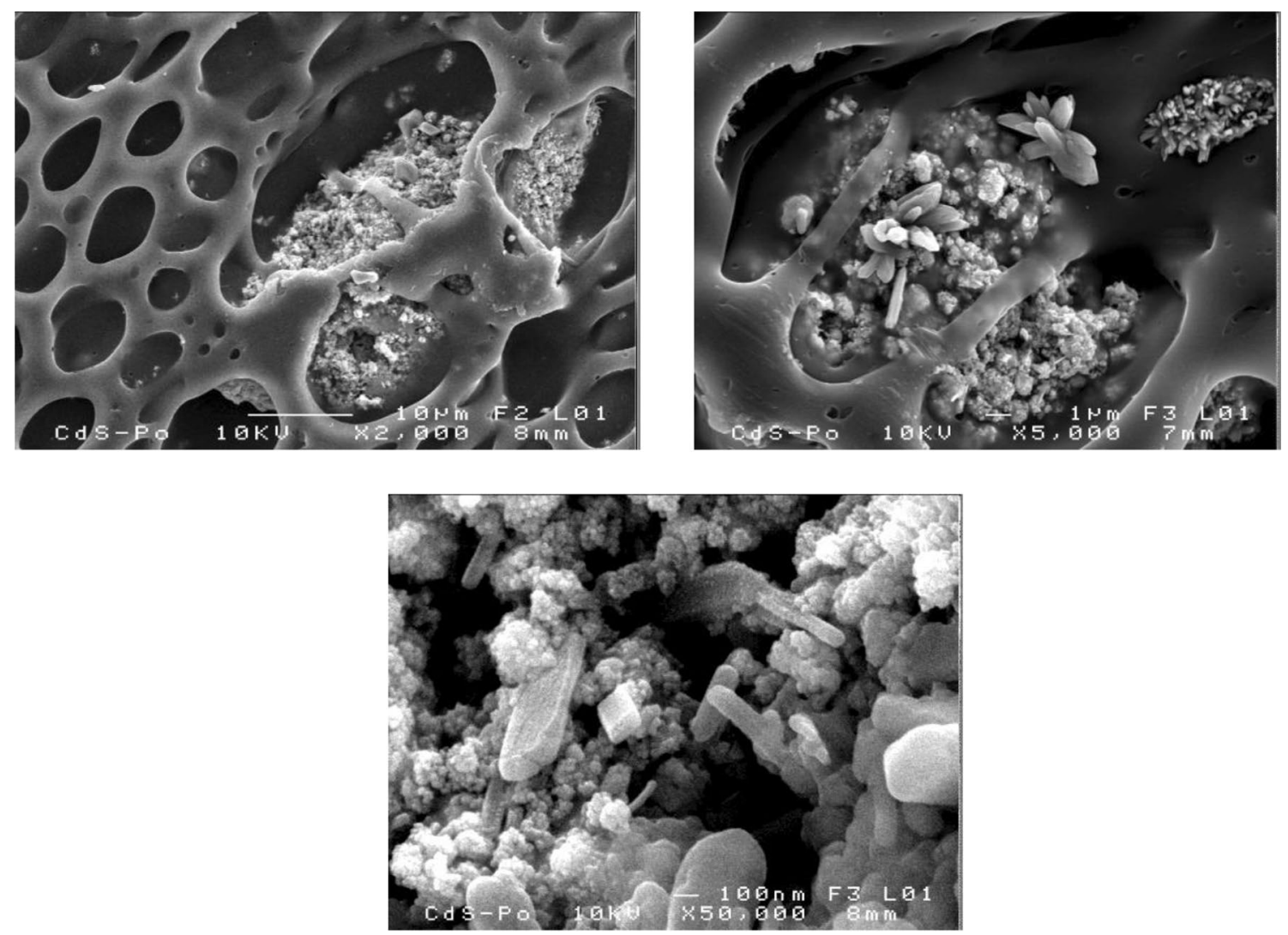

Fig. 4 SEM image of PVC 5\% CdS thin film 
slight absorption that may be due to structural defects created during processing.

\subsubsection{Optical Gap}

The optical band gap of PVC/CdS nanocomposites has been determined by plotting $(\alpha \mathrm{h} \nu)^{2}$ as a function of the incident energy (hv) which are linear over a wide range of photon energies indicating the direct type of transitions. The intercepts of these plots (straight lines) on the energy axis give the energy bandgap [15], Fig. 6.The estimated values of $E_{g}$ listed in Table 2, was obtained by the extrapolation of the straight line to $\alpha=0$. As CdS content increases, the $\mathrm{E}_{\mathrm{g}}$ value decreases from 4.07 to $3.85 \mathrm{eV}$.These band gap value differences of PVC/CdS nanocomposite inform us about the presence of CdS crystallites in the PVC matrix and confirm the results obtained previously.

\subsubsection{Photoluminescence Analysis}

Photoluminescence spectra of the samples have been recorded at an excitation wavelength of $320 \mathrm{~nm}$ and shown in Fig. 7.The spectra of PVC shows the non-emission peak. However, in the PVC/CdS nanocomposite spectra, the yellow emission band has been observed at $560.52 \mathrm{~nm}(2.97 \mathrm{eV})$ correspondent to the interstitial cadmium defect states [16]. In $\mathrm{CdS}$ nanoparticles, the defects types that contribute to the PL emission are interstitial cadmium, interstitial sulfur, cadmium vacancy and sulfur vacancy [17]. Furthermore, from Fig. 7 it can be seen that the PL intensity decreases as a function of $\mathrm{CdS}$ content which can be explained by the reduction of the electron-hole recombination rate, and this enhances the photocatalytic efficiency.

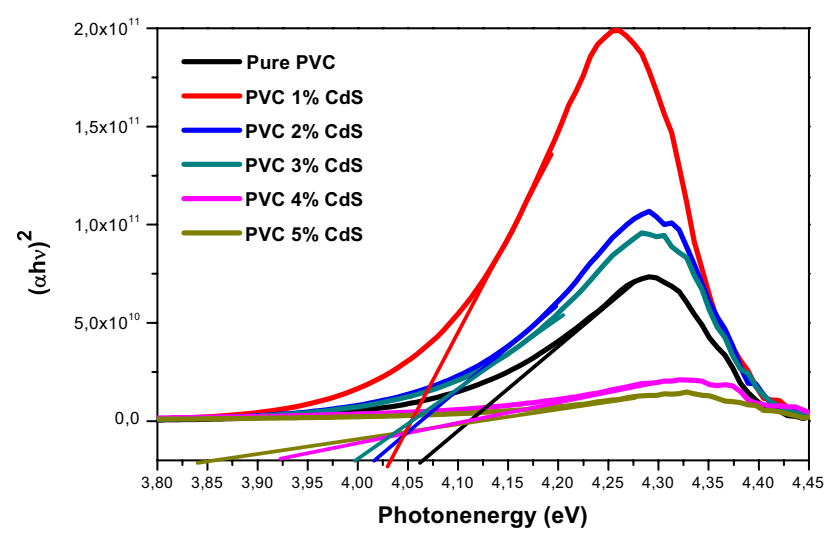

Fig. 6 The plot $(\alpha h v)^{2}$ versus incident energy (hv)
Table 2 Thicknesses and gap energy $\left(\mathrm{E}_{\mathrm{g}}\right)$ of PVC/CdS nanocomposites thin films

\begin{tabular}{lll}
\hline Samples & $\begin{array}{l}\text { Thicknesses } \\
(\mathrm{nm})\end{array}$ & $\mathrm{E}_{\mathrm{g}}(\mathrm{eV})$ \\
\hline Pure PVC & 260 & 4.07 \\
PVC 1\% CdS & 260 & 4.04 \\
PVC 2\% CdS & 225.09 & 4.02 \\
PVC 3\% CdS & 233 & 4.00 \\
PVC 4\% CdS & 221.34 & 3.92 \\
PVC 5\% CdS & 239.52 & 3.85 \\
\hline
\end{tabular}

\subsection{Photocatalytic Tests}

Figure 8 showing the decrease of the absorption spectra of methylene blue solution at $663.5 \mathrm{~nm}$, catalyzed by pure $\mathrm{PVC}$ and PVC/CdS nanocomposites under the UV light irradiation with the wavelength of during $3 \mathrm{~h}$. First of all, we perform the direct photolysis of MB and the obtained result was considered negligible as only less than $5 \%$ of degradation was achieved after $4 \mathrm{~h}$ of UV irradiation. So, the decrease indicates that both pure PVC and PVC/CdS nanocomposites exhibit UV light photocatalytic activity.

The PVC/CdS nanocomposites show much higher photocatalytic activity due to the more efficient decolorization of MB over CdS nanoparticles. As the CdS content on the nanocomposites surface increases, the photocatalytic activity of PVC/CdS nanocomposites enlarge. PVC 5\% $\mathrm{CdS}$ demonstrates the highest photocatalytic activity, displays the greatest photocatalytic activity as there is almost no absorption of the methylene blue solution after $2 \mathrm{~h}$. The concentration of MB solution was obtained by a calibration curve. Photocatalytic degradation was calculated based on Eq. (1) [18]

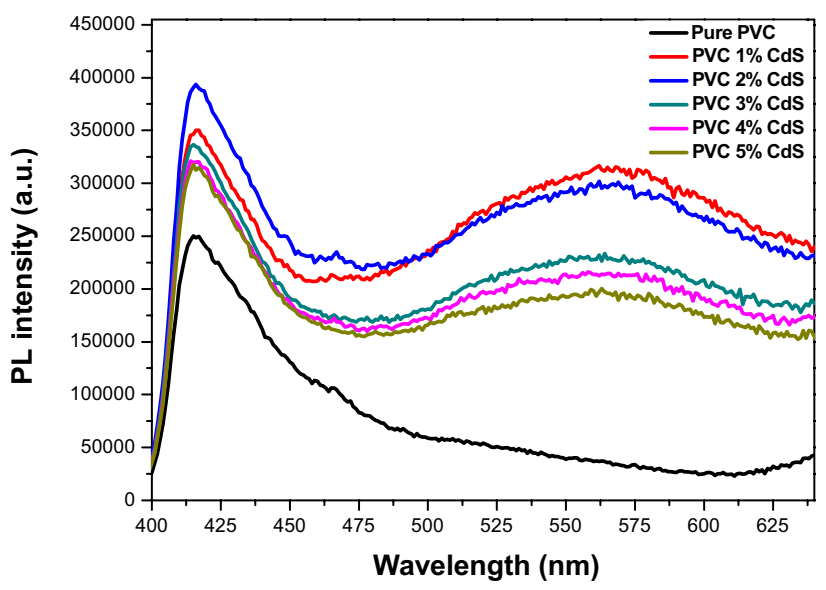

Fig. 7 PL spectra of PVC and PVC doped CdS nanoparticles 
Fig. 8 Absorption spectra of MB dye at UV light irradiation with the wavelength of during $3 \mathrm{~h}$ using pure $\mathrm{PVC}$ and $\mathrm{PVCl}$ CdS nanocomposites photocatalyst; a Pure PVC; b PVC $1 \%$ CdS; c PVC $2 \%$ CdS; d PVC $3 \%$ CdS; e PVC $4 \%$ CdS; f PVC $5 \% \mathrm{CdS}$

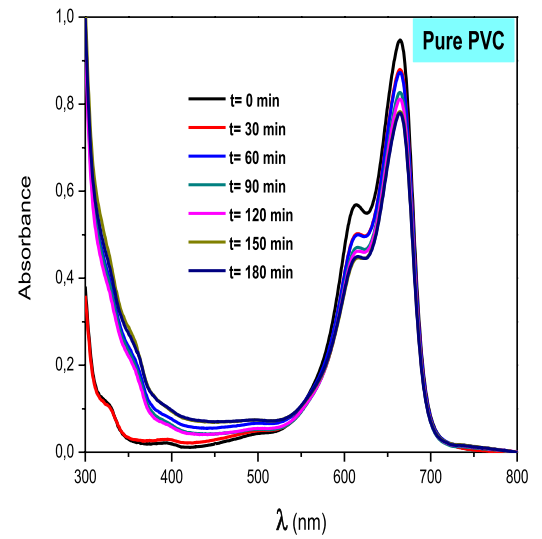

(a)

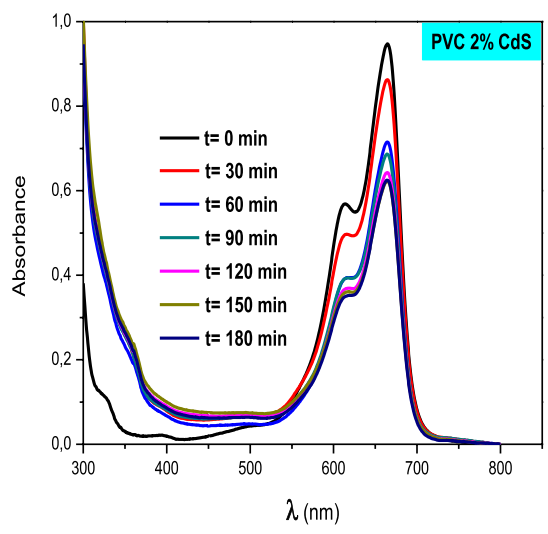

(c)

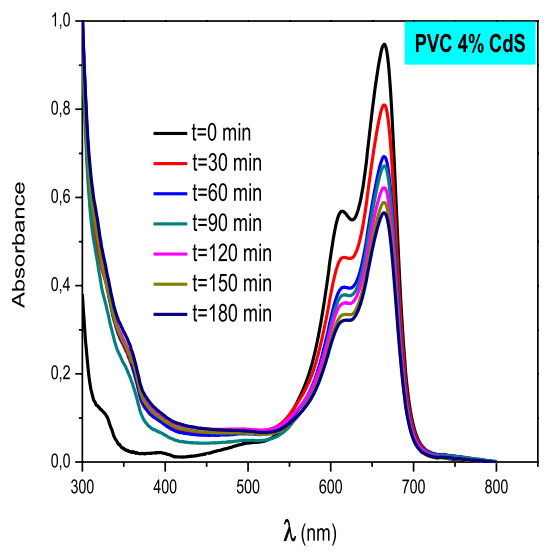

(e)

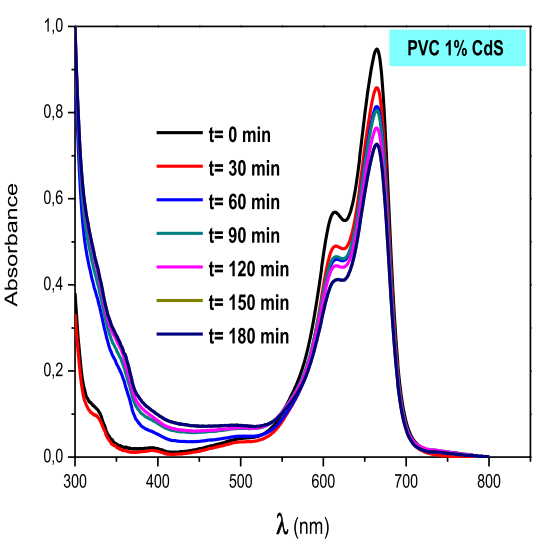

(b)

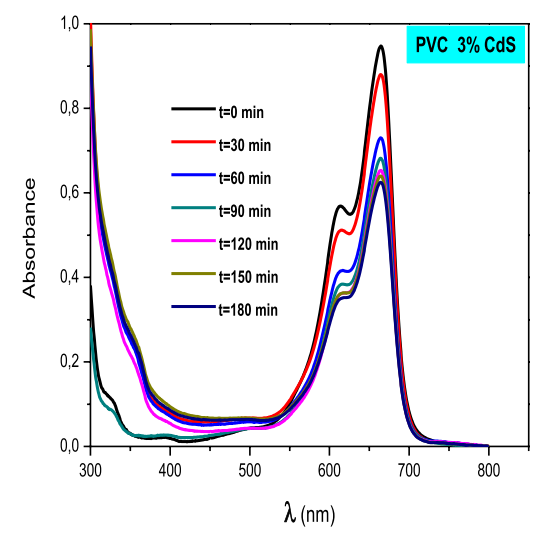

(d)

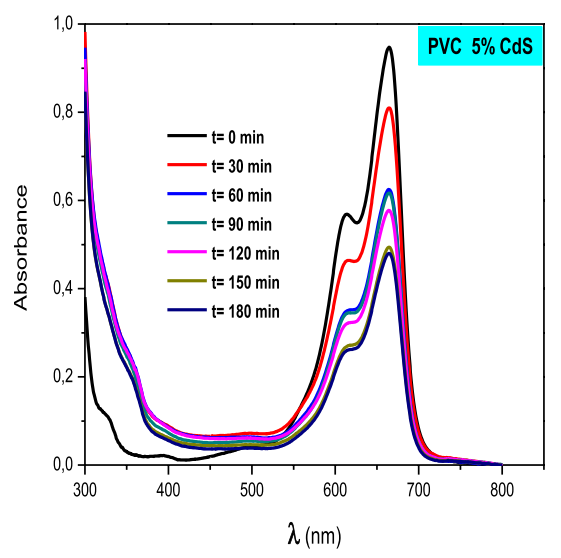

(f)
\% Degradation efficiency $=\left[\left(\mathrm{C}_{0}-\mathrm{C}\right) / \mathrm{C}_{0}\right] \times 100$

where, the symbols of $\mathrm{C}_{0}$ and $\mathrm{C}$ are the concentration of $\mathrm{MB}$ solutions before and after photo irradiation, respectively. The degradation rate of both MB solutions under UV irradiation for $3 \mathrm{~h}$, are illustrated in Fig. 8a-c
Figure 9 shows the efficiency of decomposition of the dyes (MB) under UV light. It has been clearly shown from the graph that a remarkable decolorization was facilitated by the CdS mainly under UV irradiation. Photodecomposition efficiency is attributed directly to the extent of the source of light absorbed by the catalyst. As shown in Fig. 9b, the rates constants increase as a function of the 
(a)

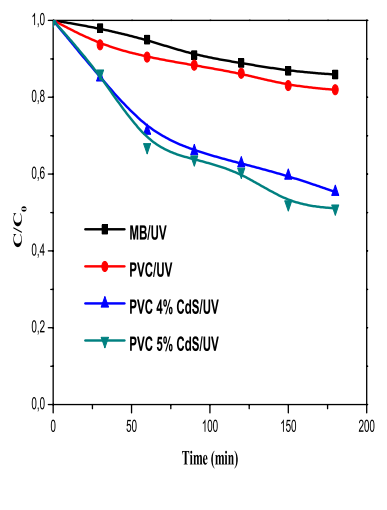

(b)

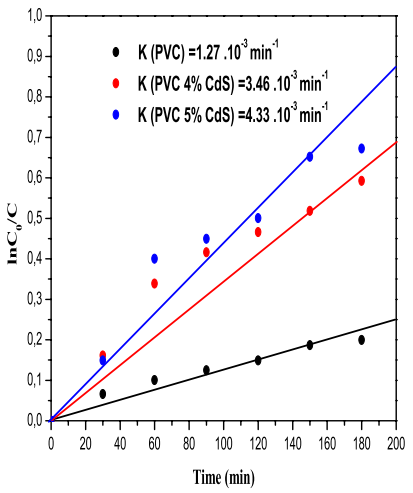

(c)

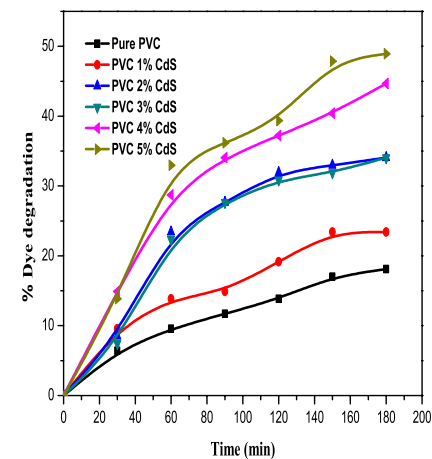

Fig. 9 Decomposition of the dyes (MB) under UV light a $C / C_{0}$ vs time $\mathbf{b} \ln C / C_{0}$ vs time $\mathbf{c} \%$ dye degration vs time

exposition time to UV. However, PVC5\%CdS films display the most improved photocatalytic performance. As can be observed in Fig. 9c, the Dye degradation increase as a function of reaction time under UV light irradiation, which indicates the producing photogenerated electrons $\left(\mathrm{e}^{-}\right)$and holes $\left(\mathrm{h}^{+}\right)$. Because of the potential differences, the LUMO of PVC can transfer to the CB of CdS nanoparticles, whereas the $\mathrm{h}^{+}$in the VB of CdS nanoparticles can transfer to the HOMO of PVC. So the separation of $\mathrm{e}^{-}$and $\mathrm{h}^{+}$in the PVC/CdS nanocomposite can be effectively enhanced, and more $\mathrm{e}^{-}$and $\mathrm{h}^{+}$can be involved in the photocatalytic reactions [19]. Through this, the process of photocatalytic efficiency of samples can be explained with the direct bandgap energy of $\mathrm{PVC} / \mathrm{CdS}$ nanocomposite which decreased from 4.07 to $3.85 \mathrm{eV}$ as the $\mathrm{CdS}$ content was increased from 0 to $5 \%$. According to PL the $\mathrm{CdS}$ doping decreased the recombination electron holes which leade to the exhibit higher photocatalytic efficiency.

\section{Conclusion}

In summary, CdS nanoparticles were doped in the PVC matrix to formed the nanocomposites films $\mathrm{PVC} / \mathrm{CdS}$ were achieved by a sol-gel method. The result of XRD and Raman revealed that $\mathrm{CdS}$ nanoparticles changes their crystalline pure PVC and indicate the dispersion of CdS nanoparticles. The transmission spectra demonstrated that the films $\mathrm{PVC} / \mathrm{CdS}$ are transparent in the visible region and the optical band gap decrease from 4.07 to $3.85 \mathrm{eV}$. Also, the analysis of SEM confirmed that the higher density of particles represents the agglomeration of CdS nanoparticles in the PVC polymer. The application of PVC/CdS nanocomposites of their photocatalysis efficiency is evaluable and consideration. Moreover, this films can be used as an excellent photocatalysis for potential application in control of environment friendly photodegradable polymer material.

\section{References}

1. S. Coiai, E. Passaglia, A. Pucci, G. Ruggeri, Nanocomposites based on thermoplastic polymers and functional nanofiller for sensor applications. J. Mater. 8, 3377-3427 (2015). https://doi. org/10.3390/ma8063377

2. V. Mathur, K. Sharma, Small angle X-ray scattering analysis of PS/CdS, PVC/CdS \& PMMA/CdS polymeric nanocomposites. JSSNT 12, 420-422 (2014). https://doi.org/10.1380/ejssn t. 2014.420

3. M.A. Ramaz Anov, Y. Babayev, Preparation and structure nanocomposites based on zinc sulfide in polyvinylchloride. J. NonOxide Glasses 10, 1-6 (2018)

4. A.A. El-Sayed, A.M. Khalil, M. El-Shahat, N.Y. Khaireldin, S.T. Rabi, Antimicrobial activity of PVC-pyrazolone-silver nanocomposites. J. Macromol. Sci. A 53, 346-353 (2016). https://doi. org/10.1080/10601325.2016.1166000

5. J.M. Meichtry, C. Colbeau-Justin, G. Custo, M.I. Litter, $\mathrm{TiO}_{2}$-photocatalytic transformation of $\mathrm{Cr}(\mathrm{VI})$ in the presence of EDTA: comparison of different commercial photocatalysts and studies by time resolved microwave conductivity. J. Appl. Catal. B 144, 189-195 (2014). https://doi.org/10.1016/j.apcat b.2013.06.032

6. P. Devendran, T. Alagesan, K. Pandian, Single pot microwave synthesis of CdS nanoparticles in ionic liquid and their photocatalytic application. Asian J. Chem. 25, S79-S82 (2013)

7. C. Yang, C. Gong, T. Peng, K. Deng, L. Zan, High photocatalytic degradation activity of the polyvinyl chloride (PVC)-vitamin C 
(VC)- $\mathrm{TiO}_{2}$ nano-composite film. J. Hazard. Mater. 178, 152-156 (2010). https://doi.org/10.1016/j.jhazmat.2010.01.056

8. D. Wang, C. Bao, Q. Luo, R. Yin, X. Lib, J. An, Z. Xu, Improved visible-light photocatalytic activity and anti-photocorrosion of CdS nanoparticles surface-modified by conjugated derivatives from polyvinyl chloride. J. Environ. Chem. Eng. 3, 1578-1585 (2015). https://doi.org/10.1016/j.jece.2015.05.013

9. A. Khorsand Zaka, W.H. Abd Majid, M.E. Abrishami, R. Yousefi, $\mathrm{X}$-ray analysis of $\mathrm{ZnO}$ nanoparticles by Williamson-Hall and sizestrain plot methods. Solid State Sci. 13, 251-256 (2011). https:// doi.org/10.1016/j.solidstatesciences.2010.11.024

10. R. Kaur, S.K. Tripathi, Study of conductivity switching mechanism of CdSe/PVP nanocomposite for memory device application. J. Microelectron. Eng. 133, 59-65 (2015). https://doi. org/10.1016/j.mee.2014.11.010

11. V.S. Solodovnichenko, V.A. Polyboyarov, A.A. Zhdanok, A.B. Arbuzov, E.S. Zapevalova, Y.G. Kryazhev, V.A. Likholobov, Synthesis of carbon materials by the short-term mechanochemical activation of polyvinyl chloride. J. Procedia Eng. 152, 747-752 (2016). https://doi.org/10.1016/j.proeng.2016.07.684

12. F. Kajzar, Organic Thin Films for Waveguiding Nonlinear Optics (CRC Press, Boca Raton, 1996), p. 829

13. J.K. Vij, Advances in Liquid Crystals, Advances in Chemical Physics (Wiley, Hoboken, 2009), pp. 259-261

14. R. Swanepoel, Determination of the thickness and optical constants of amorphous silicon. J. Phys. E 16, 1214-1222 (1983). https://doi.org/10.1088/0022-3735/16/12/023
15. M. Caglar, Y. Caglar, S. Ilican, The determination of the thickness and optical constants of the $\mathrm{ZnO}$ crystalline thin film by using envelope method. J. Optoelectron. Adv. Mater. 8, 1410-14130 (2006)

16. S. Chaure, N.B. Chaure, R.K. Pandey, A.K. Ray, Stoichiometric effects on optical properties of cadmium sulphide quantum dots. IET Circ. Devices Syst. 1, 215-219 (2007). https://doi. org/10.1049/iet-cds:20070048

17. V. Singh, P. Chauhan, Structural and optical characterization of CdS nanoparticles prepared by chemical precipitation method. J. Phys. Chem. Solids 70, 1074-1079 (2009). https://doi. org/10.1016/j.jpcs.2009.05.024

18. D. Wang, L. Shi, Q. Luo, X. Li, J. An, An efficient visible light photocatalyst prepared from $\mathrm{TiO}_{2}$ and polyvinyl chloride. J. Mater. Sci. 47, 2136-2145 (2012). https://doi.org/10.1007/s1085 3-011-6014-6

19. G. Nie, G. Li, L. Wang, X. Zhang, Nanocomposites of polymer brush and inorganicnanoparticles: preparation, characterization and application. Polym. Chem. 4, 753-769 (2016). https://doi. org/10.1039/C5PY01333J

Publisher's Note Springer Nature remains neutral with regard to jurisdictional claims in published maps and institutional affiliations. 